\title{
Human life saving lifelines and cost-effective design of an exclusive water supply system for fires following earthquakes
}

\author{
S. Takada \& Y. Kuwata \\ Department of Civil Engineering, Kobe University, Japan
}

\begin{abstract}
This paper investigates the effects of the lifeline malfunction on the loss of human lives during the 1995 Kobe earthquakes. Firstly those effects were reviewed for firefighting and hospital waters relating to water supply lifelines. Those lives which might have been saved if the water lifelines had worked shortly after the earthquake are analyzed based on the records of firefighting operation and have been counted as approximately 32 to 45 people. Next, an exclusive water supply system for firefighting introduced into fire fragile areas after the earthquakes is designed giving basic procedures based on costeffectiveness.
\end{abstract}

Keywords: lifeline, firefighting.

\section{Introduction}

Lifeline is categorized into four systems; energy supply system, water supply and treatment system, transportation system and information system, which are essential infra-structures for social activity, especially in urban livelihood. As a lesson from the 1995 Kobe earthquake, we learned that human lives might be lost as a result of the lifeline malfunctions in an emergency situation after earthquakes; for examples, traffic congestion of telecommunication system in the search and rescue (SAR) activity, no firefighting water from hydrant, traffic congestion in transporting earthquake injuries and the lifeline malfunction in emergency medical care centers.

This paper investigates how the lifeline malfunction affected the loss of human lives during the 1995 Kobe earthquakes. Effects related to water supply lifelines were reviewed. Especially on the stage of fires following earthquake, 
those who might be saved if water lifeline had worked shortly after the earthquake are counted based on the records of firefighting activity. Then, an exclusive water supply system for firefighting introduced into fire fragile areas after earthquakes is designed giving basic procedures based on costeffectiveness.

\section{Loss of human lives related to water supply lifelines}

\subsection{Firefighting water}

More than 300 fires occurred following the 1995 Kobe earthquake causing the deaths of approximately 550 people among 6,434 earthquake casualties. Causes of ignition are thought to be the turning of stove, gas leakage and the round area-block restoration of electric power without checking individual house condition. Many factors such as traffic congestion hampering the transportation of fire engines and no water from hydrants, which are installed in the drinking water supply system, led to the urban conflagration. There is duty for the fire department to prepare fire protection environment; however the lack of water from hydrants attached to drinking water supply systems operated by Kobe City Water Bureau made the fire grow in a large area.

Figure 1 depicts 52 locations of the fires causing burnt deaths in Kobe city during the earthquake [1]. The circle size indicates the number of casualties. Large victims were concentrated in the west part of Kobe City.

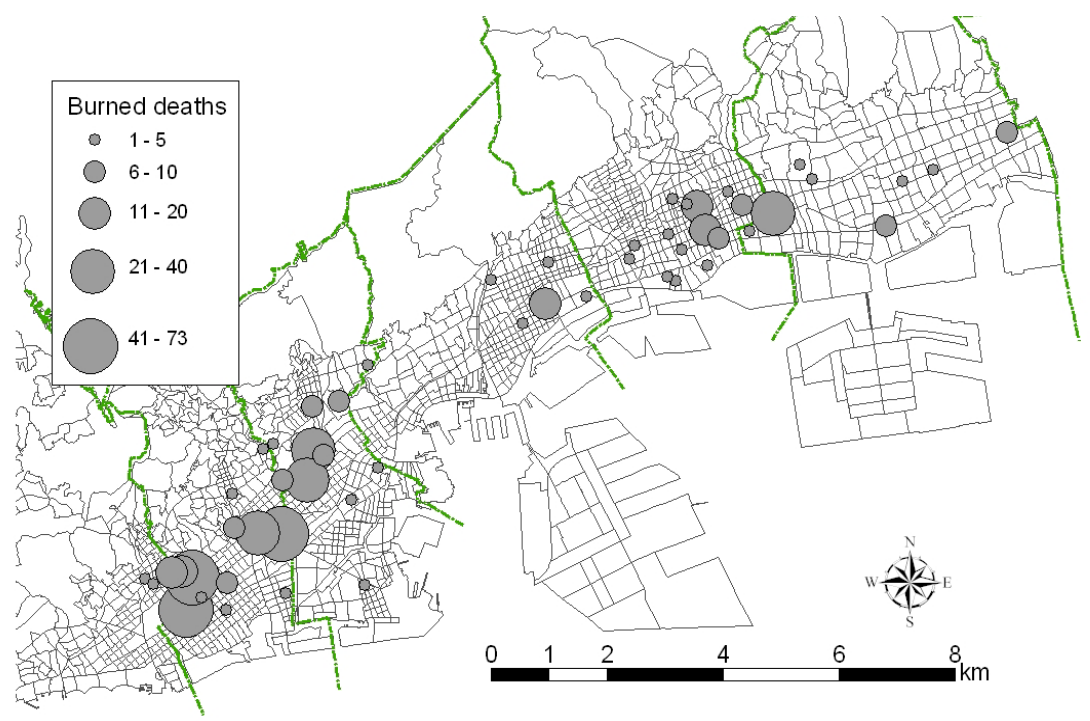

Figure 1: Victims by fires during the 1995 Kobe earthquake. 


\subsection{Water in medical care centre}

A lot of hospitals had major damage to their building and medical facilities and lost function of emergency medical care in the 1995 Kobe earthquake. Here a case for the main hospital called Kobe City General Hospital is shown in detail. The hospital located on an artificial island, Port Island in Kobe bay is one of the biggest hospitals in Kobe City and normally accepts 2,535 ambulatory patients and 959 hospitalized patients per a day. Main structure of the building with 12 stories constructed in 1980 had slight earthquake damage, thanks to the seismic countermeasures for liquefaction. However, hospital lifelines and interior equipments could not be of use.

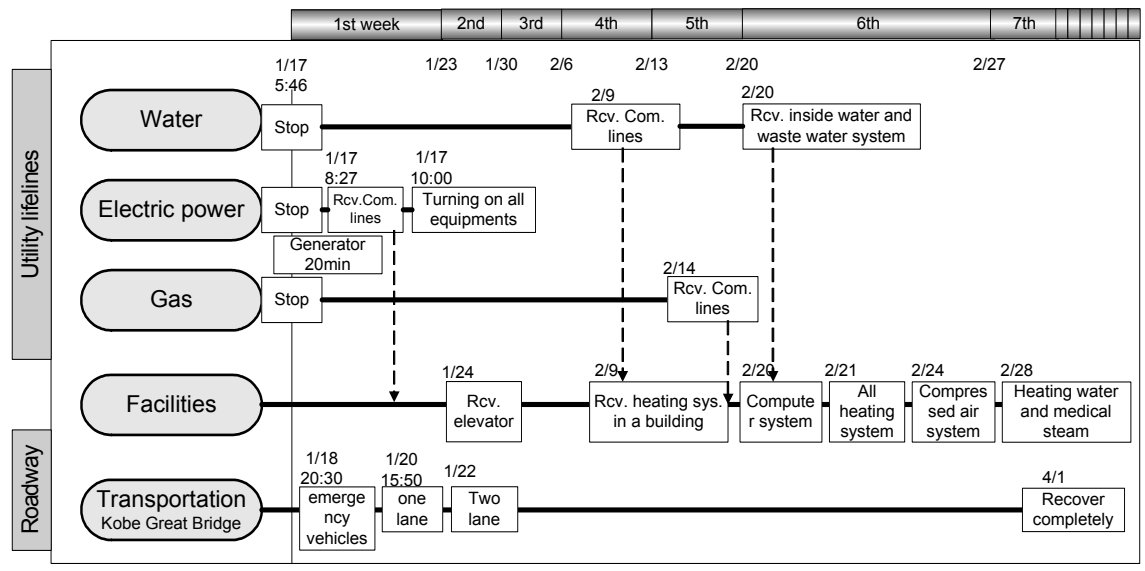

Figure 2: Restoration process of hospital lifelines in Kobe City General Hospital during the 1995 Kobe earthquake.

There were several breaks and leaks in the municipal water pipelines from distributing water reservoirs via the Kobe Great Bridge to the hospital, by destructive strong ground motion and liquefaction. In the hospital, an elevated water tank for drinking $\left(80 \mathrm{~m}^{3}\right)$ and its piping were damaged, and an elevated water tank for miscellaneous use $\left(60 \mathrm{~m}^{3}\right)$ was cracked. Due to water leaked from these tanks, the water supply system to pump water up to the elevated tanks was automatically switched on, and water in a receiving tank located on the ground drained. There was no useful water inside the hospital. Immediately after the earthquake, water companies and Self Defense Force delivered water tanks with 20 tons a day, which was not enough compared with daily use of 700 to 900 tons. Although the pipeline outside the hospital was repaired in 3 weeks after the earthquake, repair of the elevated water tanks needed another 1 week. When the inside water supply system was completely repaired, most medical equipments and machineries restarted gradually as shown in Figure 2. In this case, the outage of water gave a significant impact on hospital sanitary environment and medical 
care operations. Many hospitalized patients were transported to other medical care centers and the hospital could not accepted ambulatory patients. The number of people who were affected by the hospital malfunction has not been made clear.

\section{Estimation of human lives saved from fires - if the water had come at hydrants}

\subsection{Case study for human lives saved from fires}

52 locations of the fires causing deaths can be divided into 7 cases in conditions of fire spread and response throughout the detailed analyses on fire growth and firefighting operation [1-4], as listed in Table 1. With respect to 6 fire locations of Case 1 listed in Table 1, the people who would have been saved if the water had come at hydrants are listed in Table 2 . We believe 32 to 45 people might have been saved out of 95 burnt people.

Table 1: $\quad$ Case study on fires causing burnt deaths in relation to fire spread and fire fighting activity.

\begin{tabular}{|c|c|c|c|c|}
\hline Case & Fire spread and response & $\begin{array}{l}\text { No. of } \\
\text { fires }\end{array}$ & Burnt & people \\
\hline 1 & $\begin{array}{l}\text { Possible to save people if water had come at } \\
\text { hydrants }\end{array}$ & 6 & & 95 \\
\hline 2 & Insuppressible against aggressive fire growth & 9 & & 110 \\
\hline 3 & $\begin{array}{l}\text { Suppressible against fire but impossible to } \\
\text { save people }\end{array}$ & 5 & & 20 \\
\hline 4 & $\begin{array}{l}\text { Insuppressible against fire due to the delay of } \\
\text { fire engine arrival }\end{array}$ & 6 & & 195 \\
\hline 5 & Burnt without fire engine arrival & 5 & & 65 \\
\hline 6 & Burnt only in one house & 4 & & 4 \\
\hline 7 & Insufficient data to analyze & 17 & & 40 \\
\hline \multicolumn{2}{|r|}{ Total } & 52 & & 529 \\
\hline
\end{tabular}

Table 2: $\quad$ Estimated human lives saved in the burnt areas.

\begin{tabular}{ccc}
\hline Burnt district & Burnt people & Possible to be saved \\
\hline \hline A & 8 & 1 to 4 \\
B & 25 & 7 to 12 \\
C & 15 & 2 to 4 \\
D & 40 & 22 \\
E & 5 & 0 to 2 \\
F & 2 & 0 to 1 \\
\hline \hline Total & 95 & 32 to 45 \\
\hline
\end{tabular}




\subsection{Case study for saved people from fires}

Followings are explanations on the analytical procedure to obtain the number of people who would be saved under the assumption that the water at the hydrants had come during the earthquake [5]. The burnt district A in Table 2 is shown as an example.

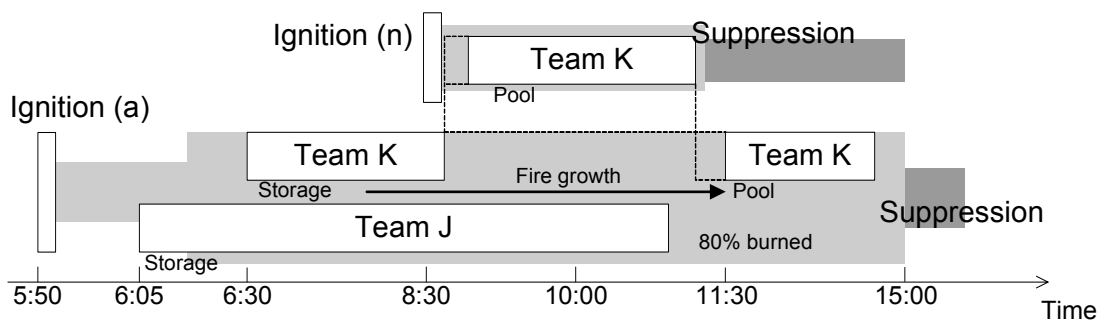

Figure 3: $\quad$ Fire operation timeline at district A.

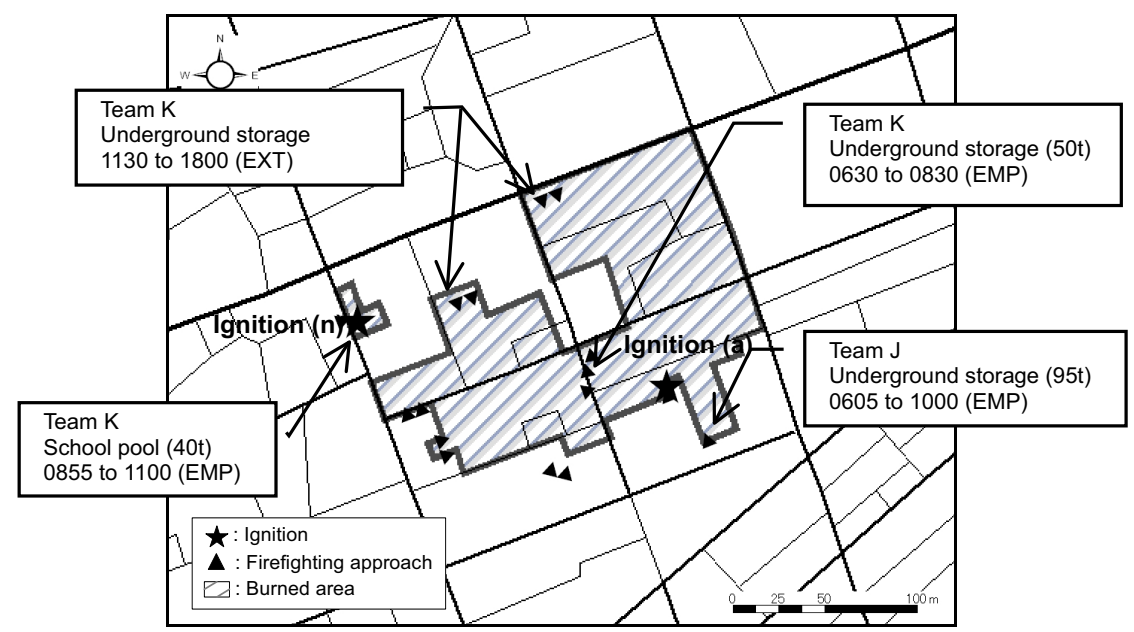

Figure 4: $\quad$ Burnt districts and fire fighting activity.

The timeline from ignition, fire spread and firefighting activities up to suppression is shown in Figure 3. In the district A, 25 people were burnt to death in the fire of ignition (a), which was ignited at 5:50 a.m. on January 17, 1995 and suppressed at 15:30 on the day with the final burnt area of approximately $30,000 \mathrm{~m}^{2}$. Figure 4 shows the burnt area and approaches of firefighting activities with water usages such as pool and underground storage. Two firefighting teams with fire engines and personnel were dispatched to this 
area by Kobe City Fire Bureau, and arrived at the district A at 6:05 a.m., 15 minutes after the ignition. One team (called Team J) carried out the firefighting activity up to 10:00 a.m., when the underground storage of water got empty. The other team (called Team K) also did from 6:30 a.m. to 8:30 a.m. until the empty of the other storage, and then moved to the other fire of ignition (n), using water in the pool at an elementary school from 8:55 a.m. to 11:00 a.m. At 11:30 a.m. Team $\mathrm{K}$ returned to the operation at the fire of ignition (a), using water of the pool.

The fact is that both of the teams could not continue the activity after 10:00 a.m. because of the lack of firefighting water from hydrants although the fire was still spreading. Assumption made herein is that the fire spread from the ignition location to the northeastern area could not be suppressed, but that to the western area could be reduced resulting in half of the burnt area, if the firefighting water had been reached at hydrants considering the operation timeline of the two teams. Then the total 25 burnt people could be decreased to 13 to 18 people considering the burnt area at the time of storage was empty and the uncertainty of their addresses. Analyses for other 5 burnt districts in the Case 1 have been made as well.

\section{Design of exclusive fire fighting water supply system}

Several countermeasures are prepared in order to maintain firefighting water after earthquakes. Kobe City Fire Bureau currently increases large underground storages of the water from the lessons of urban conflagrations during the 1995 Kobe earthquakes. On the other hand, AWWS (Auxiliary Water Supply System) in San Francisco and DFPS (Dedicated Fire Protection System) in Vancouver are water supply systems dedicated for firefighting constructed after the huge earthquakes [6]. They play the role of back-up function for water from hydrants attached to drinking water supply systems.

Here an exclusive water supply system dedicated for firefighting (here after called EWSS) is introduced to a part of Kobe City as one of countermeasures for fires following earthquakes. Figure 5 shows the basic concept designing the EWSS. The design can be done by following steps: (1) determination of a fire hazard area for the system installed, (2) estimate of water volume required for firefighting, (3) selection of water source, (4) hydrants allocation, and (5) design of pipeline system considering hydraulic reliability and cost benefit.

Figure 6 shows water supply districts with percentage of anti-seismic pipelines improved after the Kobe earthquake [7]. The target area for EWSS installed is determined considering factors on inflammable wooden houses, weak pipelines and locations of disaster related public organizations [8].

The required firefighting water is counted by predicting the number of ignitions and fire spread under the most severe conditions of seasons and hours based on the experiences in the previous earthquakes in Japan as well as in the Kobe earthquake. Table 3 shows the parameters used for estimating the required water volume against the ignitions of fire type. One of reservoirs of the drinking water supply system, currently out of use, is selected as the water source of 
EWSS after comparing cost and performance with the case of water sources by the existing water transmission tunnel.

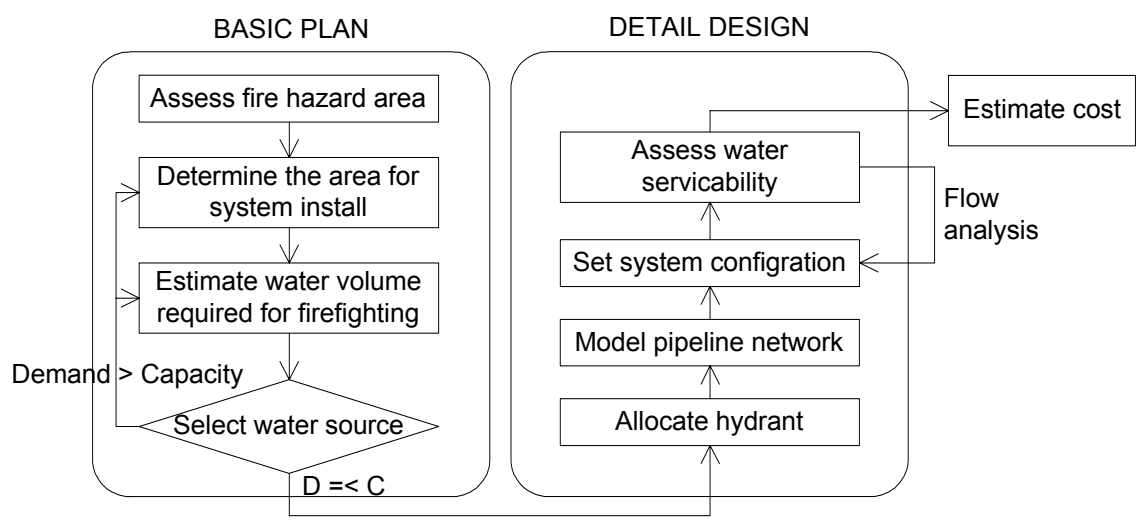

Figure 5: Design of exclusive fire fighting water supply system.

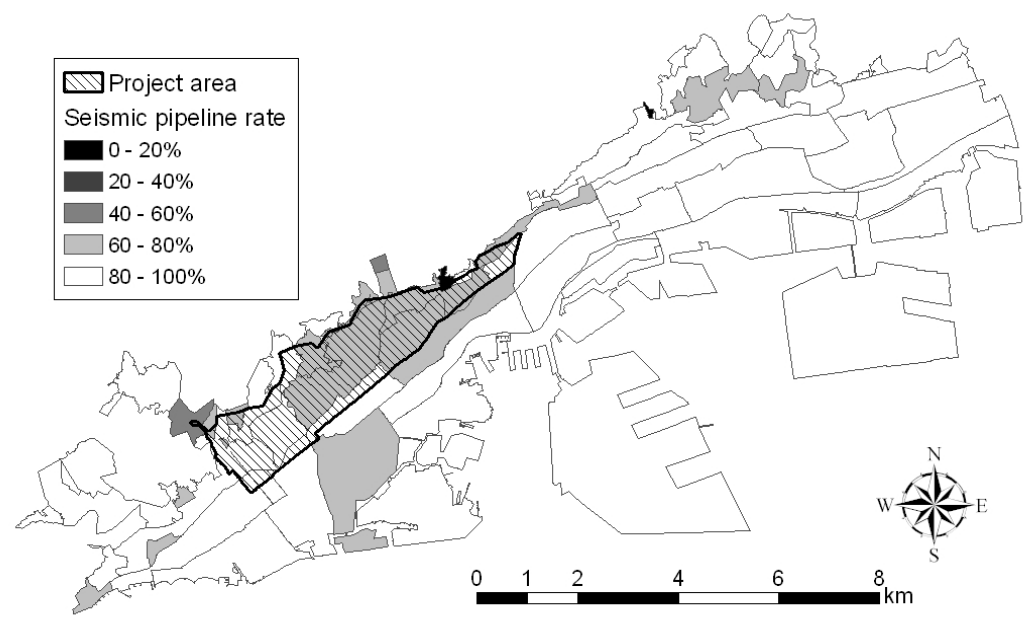

Figure 6: Water supply districts with percentage of anti-seismic pipeline. 
Table 3: Required firefighting water against an ignition of fire type

\begin{tabular}{lrr}
\hline & Fire within house & Conflagration \\
\hline \hline Burnt area $\left(\mathrm{m}^{2}\right)$ & 120 & 6,800 \\
Burnt perimeter $(\mathrm{m})$ & 53 & 476 \\
Average perimeter for fire engine $(\mathrm{m})$ & 8 & 15 \\
Number of hydrants for water use & 3.2 & 15.6 \\
Watering time (min.) & 79 & 1,328 \\
Required water volume for firefighting $\left(\mathrm{m}^{3}\right)$ & 157 & 10,624 \\
\hline
\end{tabular}

A pipeline network model with hydrants has been proposed based on hydraulic flow analyses, which gives appropriate pipe diameters to satisfy the pressure of firefighting water. The proposed pipeline network at minimum cost is shown in Figure 7. The cost for the EWSS install is 90.5 billion US\$ as listed in Table 4.

The verification of the cost effectiveness of the proposed EWSS was discussed from the view points of other countermeasures such as the construction of large underground storages of water under several scenarios of earthquake. Please refer other our papers [9].

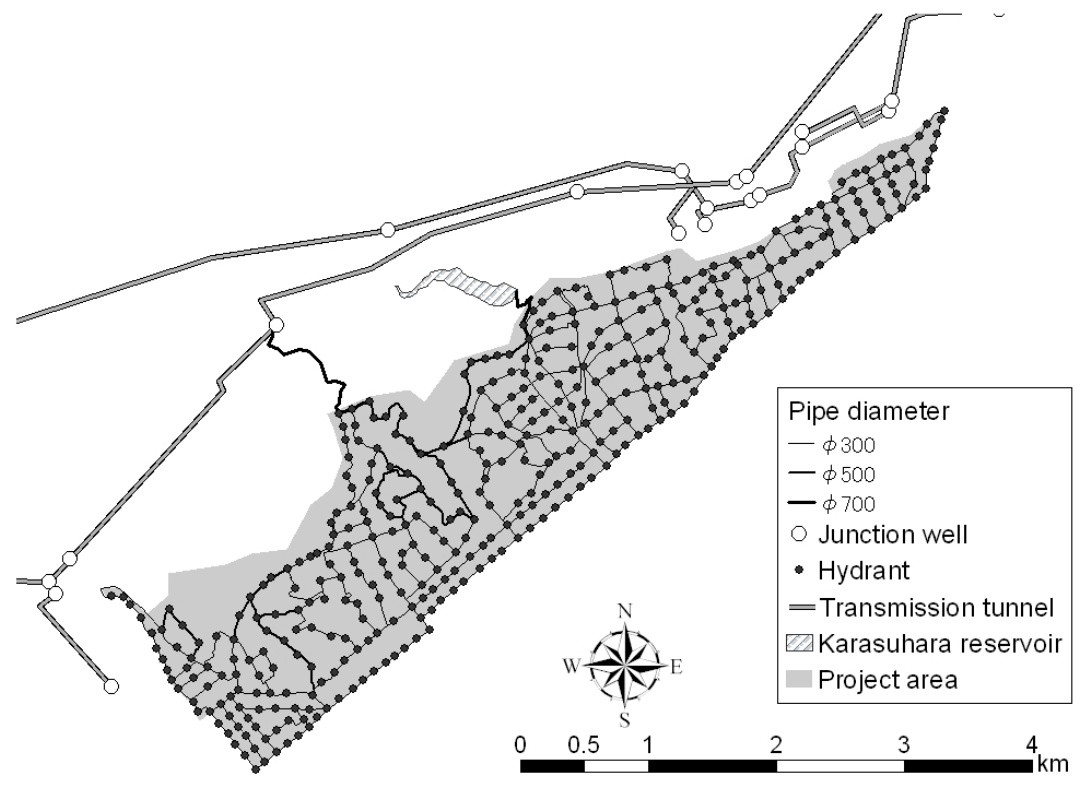

Figure 7: $\quad$ Proposed model of EWSS. 
Table 4: $\quad$ Cost estimated for the EWSS install.

\begin{tabular}{rrrrr}
\hline & Unit price (US\$/m) & $\begin{array}{c}\text { Pipe length }(\mathrm{m}) \text { or } \\
\text { pump head }(\mathrm{m})\end{array}$ & Cost (US\$) \\
\hline Pipeline & $\varphi 300$ & 1,080 & 62,634 & 67.8 \\
& $\varphi 500$ & 1,667 & 8,534 & 14.3 \\
& $\varphi 700$ & 2,333 & 1,482 & 3.5 \\
\multicolumn{2}{c}{ Subtotal } & & 72,651 & 85.5 \\
\multicolumn{2}{l}{ Pump } & 83,333 & 60 & 5.0 \\
\hline \multicolumn{2}{c}{ Total } & & & 90.5 \\
\hline
\end{tabular}

\section{Conclusive remarks}

This paper discussed the importance of human life safety related to lifelines during earthquakes. Effects due to malfunction of the water supply lifelines are reviewed on firefighting water and hospital lifelines for emergency medical cares. Followings can be concluded as the results of this paper.

Those who would be saved if water lifeline had worked well shortly after the 1995 Kobe earthquake are analyzed based on the records of firefighting activity and counted as approximately 32 to 45 human lives.

A cost effective design procedure and an application for an exclusive firefighting water supply system (EWSS) have been proposed considering earthquake fire hazard and hydraulic efficiency.

\section{References}

[1] Japan Association for Fire Science and Engineering (eds.), Investigating report on fires in the 1995 Kobe earthquake, 1996 (Jp).

[2] Kobe City Water Bureau, Report on firefighting activity during the HanshinAwaji earthquake disaster, No.1, Gyosei, 1996 (Jp).

[3] Yasuno, K. \& Hayakawa, T., Fire and water supply system, ed. Japan Water Research Center, 2001 (Jp).

[4] Lifeline Network, Kansai (ed.), Lessons from Hanshin-Awaji Earthquake, Proc. of Symposium on Disaster Prevention and Mitigation, pp.141-146, 1997 (Jp).

[5] Takada, S., Gonsoku, Y. \& Kuwata, Y., Fire spreading and casualty due to outage of water at hydrants, Journal of Japan Association for Earthquake Engineering, 5(2), pp.1-15, 2005 (Jp with Eng abstract).

[6] Scawthorn, C., Fire following earthquakes (chapter 29). Earthquake Engineering Handbook, eds. Wai-Fah Chen \& Charles Scawthorn (eds.), CRC press, 2003.

[7] Kobe City Water Bureau, Personal communication, 2005.

[8] Kobe City Disaster Prevention Council, Kobe City Urban Planning for Disaster, 2005 (Jp).

[9] Takada, S. Kuwata, Y. \& Gonsoku, Y., Cost-effectiveness analysis for instruction of dedicated water supply system for firefighting, Journal of Japan Association for Earthquake Engineering (submitted). 